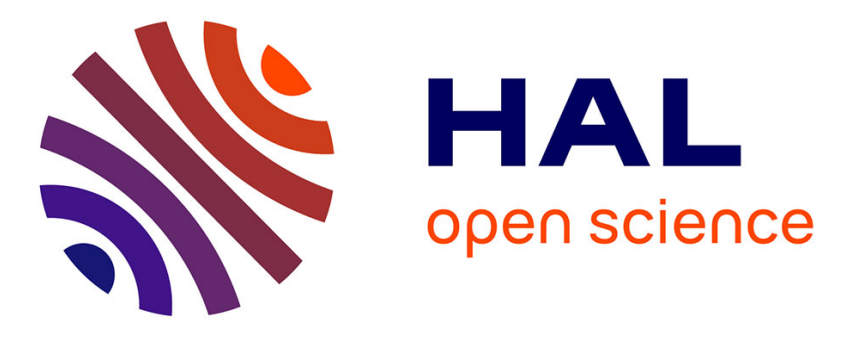

\title{
Chemical tailoring of Single Molecule Magnet behavior in films of Dy(III) dimers
}

Irene Cimatti, Xiaohui Yi, Roberta Sessoli, Marin Puget, Boris Le Guennic, Julie Jung, Thierry Guizouarn, Agnese Magnani, Kevin Bernot, Matteo Mannini

\section{To cite this version:}

Irene Cimatti, Xiaohui Yi, Roberta Sessoli, Marin Puget, Boris Le Guennic, et al.. Chemical tailoring of Single Molecule Magnet behavior in films of Dy(III) dimers. Applied Surface Science, 2018, 432 (Part A), pp.7-14. 10.1016/j.apsusc.2017.06.024 . hal-01655640

\section{HAL Id: hal-01655640 https://hal-univ-rennes1.archives-ouvertes.fr/hal-01655640}

Submitted on 5 Dec 2017

HAL is a multi-disciplinary open access archive for the deposit and dissemination of scientific research documents, whether they are published or not. The documents may come from teaching and research institutions in France or abroad, or from public or private research centers.
L'archive ouverte pluridisciplinaire HAL, est destinée au dépôt et à la diffusion de documents scientifiques de niveau recherche, publiés ou non, émanant des établissements d'enseignement et de recherche français ou étrangers, des laboratoires publics ou privés. 


\section{Chemical tailoring of Single Molecule Magnet behavior in films of Dy(III) dimers}

Irene Cimatti ${ }^{*}$ irene.cimatti@unifi.it, Xiaohui Yi ${ }^{\mathrm{b}}$, Roberta Sessoli ${ }^{\mathrm{a}}$, Marin Puget $^{\mathrm{b}}$, Boris le Guennic $^{c}$, Julie Jung ${ }^{c}$, Thierry Guizouarn ${ }^{c}$, Agnese Magnani ${ }^{d}$, Kevin Bernot ${ }^{b^{*}}$

Kevin.Bernot@insa-rennes.fr, Matteo Mannini ${ }^{\mathrm{a}}$

${ }^{\text {a }}$ Department of Chemistry, University of Florence \& INSTM RU of Florence, 50019 Sesto Fiorentino, Italy.

${ }^{\mathrm{b}}$ Institut des Sciences Chimiques de Rennes, UMR 6226 CNRS, INSA Rennes, 20 Av. des Buttes de Coësmes, 35708 Rennes Cedex, France.

${ }^{\mathrm{c}}$ Institut des Sciences Chimiques de Rennes, UMR6226 CNRS, Université de Rennes 1, 263 Av. du General Leclerc, 35042 Rennes Cedex, France.

${ }^{\mathrm{d}}$ Department of Biotechnology, Chemistry and Pharmacy, University of Siena \& INSTM RU of Siena, via Aldo Moro, 2, 53100 Siena, Italy.

* Corresponding authors at: Department of Chemistry, University of Florence, Via della Lastruccia 3, 50019 Sesto Fiorentino, Italy and Institut des Sciences Chimiques de Rennes, UMR 6226 CNRS, INSA Rennes, 20 Av. des Buttes de Coësmes, 35708 Rennes Cedex, France. 


\section{Highlights}

- Chemical tuning of the structure of a Dy-dimer enhances its Single Molecule Magnet behaviour

- The new complex can be sublimated intact as thin film

- The magnetic behaviour of the complex is fully preserved after the sublimation 


\begin{abstract}
The insertion of Single Molecule Magnets (SMMs) in spintronic devices has drawn much attention thanks to their fascinating quantum and classical magnetic properties. Although many efforts have been done in this direction, we are still in search of optimal molecules, which preserve intact the magnetic bistability at the nanoscale. In this frame, we have synthesized a new dysprosium-based dimer characterized by SMM behavior and a doublebutterfly-shape hysteresis. The complex has been successfully deposited intact by sublimation in high vacuum and the peculiar SMM behavior of the complex is fully retained at the nanoscale demonstrating that a modification of the dimer structure aimed for enhancing the SMM character is compatible with nanostructuration purposes.
\end{abstract}

Keywords: Single Molecule Magnet, Dysprosium, X-ray photoelectron spectroscopy, Timeof-Flight Secondary Ion Mass Spectrometry, magnetic bistability, thin film 


\section{Introduction}

Single Molecule Magnets (SMMs) are fascinating coordination mono and polynuclear complexes exhibiting magnetic bistability that has purely molecular origin [1,2]. Their peculiar combination of quantum and classical properties makes them ideal candidates to be integrated in devices for spintronics and quantum computing [3-5]. The integration of these objects in hybrid architectures is achieved by their deposition on specific surfaces carefully controlling that these fragile systems maintain unaltered their magnetic properties [6,7].

There are a limited number of SMMs retaining their magnetic behavior at the nanoscale. Among them, the tetrairon(III) system $\left(\mathrm{Fe}_{4}\right)$ [8] is a very interesting molecule that can be properly functionalized $[9,10]$ and deposited on the substrate using wet chemistry strategies $[11,12]$ as well as by organic molecular beam deposition (OMBD) methods [13,14]. Another class of SMMs extensively studied is the one of Terbium(III) bisphthalocyaninato complexes [15] that resulted even more stable and, more importantly, characterized by a magnetic bistability that is retained at higher temperature. However, different studies highlight the erratic magnetic behavior of such molecules, that can be positively influenced by certain substrates [16], but in other cases experience a significant acceleration of the magnetization dynamics [17,18]. This justifies the effort in selecting new SMM candidates maintaining their behavior at the nanoscale and possibly with improved magnetic performances. Among the many synthesized SMMs, lanthanide-based dimers [19-43] have been widely studied because they offer a nice platform to investigate magnetic couplings between two lanthanide ions $[42,44]$. We recently demonstrated that such dimer of formula Dy(hfac) $\left.)_{3}(\mathrm{PyNO})\right]_{2}[45]$ (where hfac $^{-}=$hexafluoroacetylacetone and $\mathrm{PyNO}=$ pyridine $N$-oxide, DyPyNO hereafter) is a particularly good candidate for the observation of SMM properties on surface. Indeed, by using muon spin relaxation measurements $(\mu-S R)$ we evidenced that the magnetic properties of this SMM are not altered neither by the metallic substrate nor by the vacuum vicinity [46]. As the magnetic behavior of most lanthanide-based dimers is extremely sensitive to slight modification in the dimer architecture [19-21,25-27,31-33,36,43] we have engaged a chemical work on the DyPyNO molecule in order to optimize its SMM behavior by introducing a $\mathrm{NO}_{2}$ electron-withdrawing group on the dimer's aromatic linker as already performed on similar molecules [37]. However the introduction of this electron-deficient group is expected to quench the fluorescence with respect to the behavior of the pristine DyPyNO molecule $[47,48]$. Indeed, no sizeable luminescence emission has been observed. 
In this work, we describe the synthesis and the magnetic studies of molecular film of $\left[\mathrm{Dy}(\mathrm{hfac})_{3}\left(\mathrm{PyNO}-\mathrm{NO}_{2}\right)\right]_{2}$ (with PyNO-NO$=4$ 4-nitropyridine $N$-oxide DyPyNO-NO2 hereafter) obtained via OMBD technique.

\section{Results and Discussion}

\subsection{Crystal structure of DyPyNO-NO2}

Single-crystal X-ray diffraction studies reveal that DyPyNO-NO2 crystallizes in a monoclinic system with the $\mathrm{P} 2{ }_{1} / \mathrm{n}$ space group (main structural parameters are gathered in table $\mathrm{S} 1$ ). The asymmetric unit contains one Dy(hfac) 3 moiety and one PyNO- $\mathrm{NO}_{2}$ ligand. Each Dy ${ }^{\mathrm{III}}$ ion is surrounded by six oxygen atoms from three hfac ${ }^{-}$ligands $(\mathrm{O} 1, \mathrm{O} 2, \mathrm{O} 4, \mathrm{O} 5, \mathrm{O} 6$ and 07$)$ and two oxygen atoms from the NO group of two PyNO-NO 2 ligands (O3). The latter connects two equivalent $\mathrm{Dy}(\mathrm{hfac})_{3}$ moieties in $\mu_{2}$ mode to form a dinuclear compound of formula $\left[\mathrm{Dy}(\mathrm{hfac})_{3}\left(\mathrm{PyNO}-\mathrm{NO}_{2}\right)\right]_{2}$ as shown in figure 1. Dy-O distances are in the 2.31-2.42 $\AA$ range (table S2) as observed on similar compounds [24,30,41]. Overall, each Dy ${ }^{\mathrm{III}}$ ion is in an almost perfect $(\mathrm{CSM}=0.551$ [49,50], table S3) square antiprism coordination environment with idealized $\mathrm{D}_{4 \mathrm{~d}}$ site geometry. The intramolecular Dy-Dy distance is quite short (4.071(4) $\AA$ ) and each dimer is fairly well isolated with the shortest intermolecular Dy-Dy distance of $10.041(2) \AA$.

\subsection{Deposition and chemical characterization of the DyPyNO-NO $\mathrm{O}_{2}$ film}

The thermogravimetric analysis of DyPyNO-NO2 (see figure S1 and Materials and Methods) shows a brutal $80 \%$ weight loss at $270^{\circ} \mathrm{C}$, suggesting that its deposition by sublimation is feasible. In order to confirm the possibility to sublimate the complex DyPyNO-NO2 we have grown several films on different substrates checking both the chemical integrity and the magnetic behavior of the complex after the sublimation. The deposition of the molecule on the substrates has been performed by sublimation in High Vacuum (HV, see Materials and Methods). The AFM analysis performed on the film grown on Au/Mica (see figure S2-S3) shows a roughness of less than $5 \mathrm{~nm}$, comparable to what observed on mica suggesting a layer-by-layer growth of the DyPyNO-NO2 on gold. A grazing incidence XRD characterization (see figure S4) of the same sample evidences the amorphous nature of the film, in analogy to what observed for the non-functionalized molecule [46]. The broad peak around $13^{\circ}$ is assigned to the molecular film, while sharper diffraction peaks can be attributable to the Au/Mica substrate. 
ToF-SIMS characterization allows a first direct comparison of the bulk material and the sublimated film. In figure 2 the spectrum of the film is compared with the pristine powder. The fragmentation pattern of these two samples is almost superimposable, giving a first demonstration of the intactness of the molecular deposit obtained by OMBD. The molecular peak is not present neither in the scratch nor in the sublimated film according to earlier reports based on similar molecules [46]. It is interesting to study the regions corresponding to the peaks [M-2hfac-PyNO-NO $]^{+}(1294 \mathrm{~m} / \mathrm{z})$ and $\left[\mathrm{M}-4 \mathrm{hfac}-\mathrm{DyPyNO}-\mathrm{NO}_{2}\right]^{+}(716 \mathrm{~m} / \mathrm{z})$, namely corresponding to the molecular fragments obtained from the loss of 2(4) hfac' ligands and one PyNO-NO $\mathrm{N}_{2}$ ligand: the isotopic distribution of these two representative peaks (figure 2) for the film and the bulk shows a good agreement with the theoretical pattern. Additionally, also the signal of the molecular peak with the loss of a hfac ligand [M-hfac] $]^{+}$at $1640 \mathrm{~m} / \mathrm{z}$ is weak but clearly visible. Further strong signals of the spectrum are due to the loss of hfac', PyNO$\mathrm{NO}_{2}$ ligands, $-\mathrm{NO}_{2}$ and fluorine such as $\left[\mathrm{Dy}(\mathrm{hfac})_{3}(\mathrm{PyNO})-\mathrm{F}\right]^{+}(857 \mathrm{~m} / \mathrm{z})$. A complete assignment of the peaks in the spectra with their intensity is given in table S4, evidencing that the same peaks have been detected in the bulk sample as well as in the sublimated sample.

Further confirmation that molecules in the sublimated film are intact is provided by an XPS analysis, being this technique capable of verifying both the stoichiometry of the molecular deposits and the valence of the elements present in the deposited molecular layers. A survey analysis reveals the presence of the expected elements constituting the DyPyNO-NO molecule. A more careful analysis of the regions of interest evidences that the spectral features of the system are completely maintained after the deposition (see figure 3, figure S5 and table S5).

In particular, the Dy $4 d$ region presents, as expected, a complex spectrum due to $4 d-4 f$ interactions. The fine structure and the main peak centered at $157 \mathrm{eV}$ are perfectly in line with a Dy ${ }^{\mathrm{III}}$ system [51,52]. The analysis of the $\mathrm{O} 1 \mathrm{~s}$ region reveals the presence of three distinct contributions attributable to the pyridine $\mathrm{N}$ oxide $(535.9 \mathrm{eV})$, the nitro group $(533.4 \mathrm{eV})$ and the ketonic (531.4 eV) oxygen, respectively [53]. The trend of the quantitative analysis of the different contributions in the region is in good correspondence with the calculated ones (see table S5). The C $1 s$ region shows a fine structure that can be clearly assigned to the different carbon atoms according to previous reports on similar complexes [46,54]: at high Binding Energy (BE), well separated with respect to the others, a peak attributable to the fluorinated carbon $\left(-\mathrm{CF}_{3}\right)$ atoms centered at $291.8 \mathrm{eV}$ can be identified. The peak at $286.4 \mathrm{eV}$ is due to the contributions of the ketonic carbon atoms $(\mathrm{C}=\mathrm{O})$ and the carbon bound to with nitrogen. The component at lower BE is the sum of the aliphatic and aromatic carbon atoms. The feature at 
$295.6 \mathrm{eV}$ is due to shake-up signal of the C $1 s$. Table S5 evidences the good agreement between the experimental and theoretical values for each component of the $\mathrm{C} 1 s$ peak. The $\mathrm{N}$ $1 s$ peak is fitted using three components: one for $-\mathrm{NO}(402.7 \mathrm{eV})$, another one for $-\mathrm{NO}_{2}$ $(405.7 \mathrm{eV})$ and a third component at lower BE $(400.1 \mathrm{eV})$ in agreement with earlier literature reports $[53,55]$. The peak at lower binding energy can be attributed to a radiation damage that is more evident in the bulk sample. The F $1 s$ peak presents a major component at $687.4 \mathrm{eV}$, due to the fluorine in the $-\mathrm{CF}_{3}$ groups, and a minor component at lower binding energy due to small radiation damage. A semi-quantitative analysis of the composition of the film according to the integrated peak signals gave the values reported in table 1 that well compares with the theoretical ones, except for dysprosium. The excess of dysprosium can be justified by the error that can be done in the fitting because of the complex peak fine structure.

The combination of the ToF-SIMS and the qualitative and semi-quantitative XPS analyses allows us to safely confirm that the DyPyNO-NO 2 film obtained by sublimation in vacuum condition is intact from a chemical point of view. This is in line with previous characterization of similar compounds [24,56] and confirms that the introduction of the $\mathrm{NO}_{2}$ group does not affect the sublimation capability of this system.

\subsection{Magnetic Measurements}

Static and dynamic magnetic susceptibility measurements have been performed on polycrystalline samples of DyPyNO-NO2 embedded in grease to avoid preferential orientation of the microcrystallites in the magnetic field. The room temperature value of the $\chi_{M} T$ product is $26.52 \mathrm{emu} \mathrm{K} \mathrm{mol}^{-1}$ at $300 \mathrm{~K}$ (figure S6), slightly lower than the expected 28.34 emu $\mathrm{K} \mathrm{mol}^{-1}$ for two isolated Dy ${ }^{\mathrm{III}}$ ions. The $\chi_{M} T$ value decreases as the temperature is lowered because of the progressive depopulation of the sublevels of the $J=15 / 2$ multiplet of the Dy ${ }^{\mathrm{III}}$ and also because of weak antiferromagnetic interactions between two Dy ${ }^{\mathrm{III}}$ centers. Such behavior was also observed on DyPyNO [45]. Ab-initio calculations evidences a very anisotropic and almost pure $m_{J}= \pm 15 / 2$ ground doublet (effective $g_{x}=0.00, g_{y}=0.01, g_{z}=$ 19.56) that is well separated from the first excited one (187 K, $\left.130 \mathrm{~cm}^{-1}\right)$ (table S6). The orientation of the magnetic axis in the molecule has been also computed by using post Hartree-Fock methods and the axis has been found to lie on an edge of the square antiprism coordination polyhedron of the Dy ${ }^{\mathrm{III}}$ ions, almost perpendicular $\left(87^{\circ}\right)$ to the Dy-Dy direction (figure 1), as seen in a similar compound [41].

From the dynamic point of view, frequency dependence of the in-phase ( $\left.\chi_{M}{ }^{\prime}\right)$ and out-ofphase $\left(\chi_{\mathrm{M}}\right.$ ”) component of the magnetic susceptibility have been measured in zero dc field 
(figure 4). Strong frequency dependence of both signals is observed and in line with what found on DyPyNO [45]. Dynamical parameters have been extracted from these measurements by fitting the $\chi_{M}$ " $v s$ frequency curves (table S7) using an extended Debye model and the relaxation times $(\tau)$ are plotted in figure 5 left [2]. Two regimes are clearly evidenced. At high temperature, the relaxation is governed by a thermally activated mechanism (Orbach relaxation process) involving excited $m_{J}$ levels. At low temperature, the Arrhenius plot flattens suggesting the onset of a different regime with a weaker temperature dependence. The nature of this latter mechanism remains unclear and recent studies points towards a key role played by low energy phonon modes [57]. We take into account the two regimes by considering the relaxation rate as the sum of two contributions with the following equation:

$$
\tau^{-1}=\tau_{0}^{-1} \exp \left(-\frac{\Delta}{k_{B} T}\right)+A T^{n} \quad \text { equ. } 1
$$

where the first term represents the Orbach process and the second term mimics a Raman process. The fitting of the data in figure 5 left with equation 1 gives the following parameters: $\tau_{0}=(3.1 \pm 1.5) \times 10^{-10} \mathrm{~s}, \Delta=204 \pm 8 \mathrm{~K}, A=0.037 \pm 0.003$ and $n=3.93 \pm 0.05$. The value obtained for the barrier of the Orbach process is slightly higher with respect to other dysprosium dimers $[58,59]$, and in particular higher that of the parent compound DyPyNO $\left(\tau_{0}\right.$ $=(6.6 \pm 2.2) \times 10^{-11} \mathrm{~s}, \Delta=166 \pm 4 \mathrm{~K}, A=0.104 \pm 0.006$ and $\left.n=4.25 \pm 0.039\right)$, as visible in table 2 and figure 5 left [46]. Moreover at $1.8 \mathrm{~K}$, the relaxation time is $\tau_{1.8 \mathrm{~K}}=2.1 \mathrm{~s}$ significantly higher than what observed on DyPyNO $\left(\tau_{1.8 \mathrm{~K}}=0.42 \mathrm{~s}\right)$. These findings confirm that the introduction of the $\mathrm{NO}_{2}$ electron-withdrawing group on the bridging ligand of the dimer is able to modify the electrostatic environment of the Dy ${ }^{\mathrm{III}}$ ion and to lead to an optimization of dimer's SMM behavior.

The distribution of the relaxation times within the sample can be estimated by a Cole-Cole plot (i.e. $\chi_{\mathrm{M}}$ " $v s \chi_{\mathrm{M}}$ ', see figure S7) where the extracted $\alpha$ parameters indicates an infinitely narrow $(\alpha=0)$ or infinitely broad $(\alpha=1)$ distribution of the relaxation times [2]. Here, almost all the dimers relax at the same rate in the thermally activated region $(\alpha=0.07$ at $15 \mathrm{~K})$ but a significant distribution of the relaxation rates characterizes the temperature-independent region ( $\alpha=0.42$ at $2 \mathrm{~K}$ ) (table S8). Additionally, a remarkable point is that almost all the sample is relaxing at low temperature as the non-relaxing fraction (that can be evaluated as $\chi_{\mathrm{S}} \chi_{\mathrm{T}}$, where $\chi_{\mathrm{T}}$ and $\chi_{\mathrm{S}}$ are the isothermal and adiabatic susceptibility respectively) is estimated to be around $4 \%$ at $1.8 \mathrm{~K}$ (see figure S7 and table S8). Overall, the DyPyNO-NO2 dimers possess an optimized SMM behavior when compared with DyPyNO (see table 2).

A similar magnetic characterization has been performed on a DyPyNO-NO2 film of $650 \mathrm{~nm}$ 
thickness deposited on a Teflon substrate (see section 3.2.). The behavior of the film, with a strong frequency dependence of both $\chi_{\mathrm{M}}$ ' and $\chi_{\mathrm{M}}$ " signals (figure 4 ) between 4 and $12 \mathrm{~K}$, is very similar to the one of the bulk material. In the high temperature and high frequencies region some spurious effects are visible as a consequence of the very low signal coming from the small amount of sample $\left(\mathrm{m}_{\text {film }}=0.3 \mathrm{mg}\right)$. These high frequency peaks can be neglected as the hysteretic magnetic behavior targeted is at extremely low frequencies or even in a static mode. Characteristic dynamic parameters have been extracted using similar procedures as for the bulk and relaxation times $(\tau)$ and their distribution $(\alpha)$ are highly similar with those of the bulk material (figure S7, table 2, S9 and S10). Very interestingly, the non-relaxing fraction is also similar. This indicates that almost all the deposited molecules are magnetically efficient. Overall, this investigation suggests that DyPyNO-NO2 has a magnetic behavior as robust as DyPyNO toward surface deposition and that the optimization of the magnetic relaxation observed on DyPyNO-NO 2 is also visible once the molecules are nanostructured as films (table 2).

To definitely probe the magnetic efficiency of films of DyPyNO-NO2 further magnetic investigation have been performed to characterize the behavior on a longer timescale. Magnetic hysteresis has been measured at $0.5 \mathrm{~K}$ with a $15.5 \mathrm{Oe} / \mathrm{s}$ sweep rate on DyPyNO$\mathrm{NO}_{2}$ derivatives in both bulk and films phases. Both hysteresis loops have the same doublebutterfly-like shape, as shown in figure 5 right. The loops adopt an S-shape close to zero-field because of the strong antiferromagnetic interaction between the Dy ${ }^{\mathrm{III}}$ ions within each dimer [30]. The opening of the hysteresis loop on the DyPyNO-NO2 film demonstrates that the magnetic bistability is successfully preserved after the sublimation. After the low-field step the loop is narrowing as a consequence of the level crossing between the first excited state and the ground state of the dimers $[37,39,42,45]$. In the Ising approximation, and treating each Dy ${ }^{\mathrm{III}}$ center as an effective spin $1 / 2$, this crossing allows to estimate the AF interaction using $\mathrm{H}_{\text {crossing }}=-j / 2 g \mu_{B}$ [45], where $j$ is the exchange constant and $g=19.56$ is the calculated gyromagnetic factor of the effective spin $1 / 2$. Given the accuracy in quantifying $\mathrm{H}_{\text {crossing, }}$ a rough estimation of $j$ is $-2.9 \mathrm{~cm}^{-1}$ for DyPyNO-NO $\mathbf{O}_{2}$ either as bulk or film. Hence, the AF coupling within the dimer is not altered by their nanostructuration in film. Overall, film and bulk hysteresis loops of DyPyNO-NO2 are almost superimposable in the low field region. This is a significant proof of the persistence of the SMM behavior of DyPyNO-NO2 once nanostructured in a film.

\section{Material and Methods}




\subsection{Synthesis}

4-Nitropyridine $\mathrm{N}$-oxide has been purchased from TCI Chemicals and used without further purification. Dy $(\mathrm{hfac})_{3} \cdot\left(\mathrm{H}_{2} \mathrm{O}\right)_{2}$ has been obtained by reported methods [60]. Dy $(\mathrm{hfac})_{3} \cdot\left(\mathrm{H}_{2} \mathrm{O}\right)_{2}$ $(0.1 \mathrm{mmol})$ is dissolved in $10 \mathrm{ml} \mathrm{CHCl}_{3}$. Then a $10 \mathrm{ml} \mathrm{CHCl}_{3}$ solution of 4-Nitropyridine $\mathrm{N}$ oxyde $(0.1 \mathrm{mmol})$ is added drop by drop. The resulting solution is stirred for $5 \mathrm{mins}$ and recovered by a layer of $n$-heptane solvent at $2^{\circ} \mathrm{C}$. After several days, crystals suitable for single-crystal X-ray diffraction are obtained. Structural data files are available as CCDC 1528789.

\subsection{Thermal Analysis}

Thermo-gravimetric and thermo-differential analyses have been performed in platinum crucibles under a nitrogen atmosphere between room temperature and $1000^{\circ} \mathrm{C}$ with a heating rate of $5^{\circ} \mathrm{C} \cdot \mathrm{min}^{-1}$ using a Perkin Elmer Pyris-Diamond thermal analyzer. At the end of the experiments, the compounds were maintained for one hour at $1000^{\circ} \mathrm{C}$ under air atmosphere in order to complete the combustion.

\subsection{X-ray Powder Diffraction}

Diagrams of DyPyNO-NO2 bulk and "cold finger" have been collected using a Panalytical $X^{\prime} P e r t$ Pro diffractometer with an $X^{\prime}$ Celerator detector. The typical recording conditions were $45 \mathrm{kV}, 40 \mathrm{~mA}$ for $\mathrm{Cu} \mathrm{K \alpha}(\lambda=1.542 \AA)$, the diagrams were recorded in $\theta-\theta$ mode between $5^{\circ}$ and $75^{\circ}$. The DyPyNO-NO$/ \mathrm{Au} / \mathrm{Mica}$ film has been investigated by grazing angle X-ray diffraction (XRD) using a $\mathrm{Cu} \mathrm{K} \alpha$ source with a Bruker D8 Advance diffractometer equipped with a focusing mirror accessory. The reported data have been obtained by placing the X-ray source between $1^{\circ}$ and $5^{\circ}$ relative to the sample plane and scanning with the detector an angle between $5^{\circ}$ and $40^{\circ}$. The pristine Muscovite mica substrate has been measured with the same instrument, using a Bragg-Brentano configuration.

\subsection{OMBD preparation and characterization}

The deposition of the molecule on the substrates is performed by sublimation in HV. We use a homemade Knudsen cell: the molecular powders are hosted in a quartz crucible heated by Joule effect by a tantalum wire. A K-type thermo-couple, buried into the powder, allows for temperature control. The sublimation rate is controlled by a quartz microbalance (QCM). During the sublimation the powders are heated up to $415 \mathrm{~K}$ reaching a deposition rate of $1.5 \AA / \mathrm{min}$. In order to confirm the rate obtained by QCM, a scratch of the film grown on $\mathrm{Au}$ 
on mica Muscovite has been measured with AFM (see figure S3), following the procedure used for similar samples [45]. We measured the film prepared for XPS presenting a nominal thickness of DyPyNO-NO2 of $50 \mathrm{~nm}$ on $80 \mathrm{~nm}$ of gold. Since the scratch a thickness is 125 nm (DyPyNO-NO 2 + gold), the value of the QCM appears reliable.

\section{ToF-SIMS}

The bulk reference has been obtained by scratching the DyPyNO-NO 2 powder on a copper foil, while the film of $\approx 33 \mathrm{~nm}$ has been deposited on a gold on mica substrate.

A TRIFT III spectrometer (Physical Electronics, Chanhassen, MN) equipped with a gold liquid-metal primary ion source was employed for the ToF-SIMS analyses. Spectra were calibrated to $\mathrm{C}_{2} \mathrm{H}_{2}{ }^{+}(\mathrm{m} / \mathrm{z}=26.0156), \mathrm{CF}^{+}(\mathrm{m} / \mathrm{z}=30.9984), \mathrm{CF}_{3}{ }^{+}(\mathrm{m} / \mathrm{z}=68.9952)$ and $[\mathrm{M}-$ 4hfac- DyPyNONO$]^{+}(\mathrm{m} / \mathrm{z}=717.9274)$. Theoretical isotopic patterns for the most relevant signals were calculated with Molecular Weight Calculator Program.

\section{XPS}

The bulk reference has been obtained by scratching the molecular powder on a carbon tape, while a film of $\approx 50 \mathrm{~nm}$ has been deposited on a gold on mica substrate. The film shows a marked charging effect due to the low conductivity of the molecular film that has been corrected using as reference the $\mathrm{C}_{\mathrm{CF}} 1 s$ peak at $291.8 \mathrm{eV}$. The inelastic background of the spectra was subtracted by means of the Shirley method [61]. Data analysis was based on a standard method for deconvolution using mixed Gaussian $(\mathrm{G})$ and Lorentzian $(\mathrm{L})$ line shapes ( $\mathrm{G}=30 \%, \mathrm{~L}=70 \%$, Gaussian-Lorentzian product) for each component in the spectrum.

XPS measurements are carried out in an UHV chamber with a base pressure in the low $10^{-10}$ mbar range. The chamber is equipped with a SPECS Phoibos 150 electron analyzer and a monochromatic Al X-ray source operating at a power of $100 \mathrm{~W}(13 \mathrm{kV}$ and $7.7 \mathrm{~mA})$. The Xray source is assembled at $54.44^{\circ}$ with respect to the analyzer. This setup has been used to characterization the sublimated film. The characterization of the scratch, used as a reference, has been performed with a standard $\mathrm{Al}$ source with a power of $100 \mathrm{~W}(10 \mathrm{kV}$ and $10 \mathrm{~mA})$. The pass energy was set to $40 \mathrm{eV}$ for all the experiments.

\subsection{Ab-initio computational details}

Wavefunction-based calculations were carried out on a model structure of [Dy(hfac) $)_{3}(\mathrm{PyNO}-$ $\left.\mathrm{NO}_{2}\right)_{2}$ (vide infra) by using the SA-CASSCF/RASSI-SO approach, as implemented in the MOLCAS quantum chemistry package (versions 8.0) [62]. In this approach, the relativistic effects are treated in two steps on the basis of the Douglas-Kroll Hamiltonian. First, the scalar terms were included in the basis-set generation and were used to determine the spin-free 
wavefunctions and energies in the complete active space self-consistent field (CASSCF) method [63]. Next, spin-orbit coupling was added within the restricted-active-space-stateinteraction (RASSI-SO) method, which uses the spin-free wavefunctions as basis states[64,65]. The resulting wavefunctions and energies are used to compute the magnetic properties and g-tensors of the lowest states from the energy spectrum by using the pseudospin $S=1 / 2$ formalism in the SINGLE-ANISO routine [66,67]. Cholesky decomposition of the bielectronic integrals was employed to save disk space and speed-up the calculations [68]. The active space of the self consistent field (CASSCF) method consisted of the nine $4 \mathrm{f}$ electrons of the Dy ${ }^{I I I}$ ion spanning the seven $4 \mathrm{f}$ orbitals, i.e. CAS(9,7)SCF. State-averaged CASSCF calculations were performed for all of the sextets (21 roots), all of the quadruplets (224 roots), and 300 out of the 490 doublets (due to software limitations) of the Dy ${ }^{\mathrm{III}}$ ion. Twenty-one sextets, 128 quadruplets, and 107 doublets were mixed through spin-orbit coupling in RASSI-SO. All atoms were described by ANO-RCC basis sets [69-71]. The following contractions were used: [8s7p4d3f2g1h] for Dy, [7s6p4d2f] for Y, [4s3p2d] for the $\mathrm{O}$ atoms of the first coordination sphere of the metal ions, [3s $2 \mathrm{p} 1 \mathrm{~d}]$ for the other $\mathrm{O}$ atoms, the $\mathrm{N}$ atoms of the PyNO groups and the $\mathrm{C}$ atoms, [3s2p] for the other $\mathrm{N}$ atoms and [2s] for the $\mathrm{H}$ atoms. The atomic positions were extracted from the $\mathrm{X}$-ray crystal structures and the $\mathrm{CF}_{3}$ groups were replaced by $\mathrm{H}$ atoms.

\section{Conclusion}

As a conclusion, we have demonstrated that the sublimable DyPyNO dimer can be modified into DyPyNO-NO 2 which shows slightly improved SMM behavior. Strong anisotropy and a relatively high energy barrier (204 K), in line with ab-initio calculations, is identified together with an extremely large fraction of relaxing molecules ( $96 \%$ of the sample at $1.8 \mathrm{~K}$ ). As its parent compounds, DyPyNO-NO2 is extremely robust toward sublimation processes as demonstrated by XPS and ToF-SIMS. Magnetic dynamic properties of the film are very similar to those of the bulk material and hysteresis loops definitely prove the robustness of the magnetic properties of the dimers once nanostructured as film. Consequently, the chemical modification of the bridging ligand of this class of evaporable SMM complexes can enhance its magnetic properties without compromising chemical stability face to sublimation and robustness of magnetic properties when nanostructured in a film.

\section{Acknowledgments}


We acknowledge financial support from ERC through the Advanced Grant "MolNanoMas" (267746) and PRIN project "RECORD" (20097X44S7). Brunetto Cortigiani is acknowledged for the assistance in the XPS characterization. B.L.G. thanks the French GENCI/IDRISCINES center for high-performance computing resources. 


\section{References}

[1] R. Sessoli, D. Gatteschi, A. Caneschi, M. Novak,;1; Magnetic bistability in a metal-ion cluster, Nature 365 (1993) 141-143.

[2] D. Gatteschi, R. Sessoli, J. Villain,;1; Molecular Nanomagnets, 2006.

[3] M. Urdampilleta, S. Klyatskaya, J.-P. Cleuziou, M. Ruben, W. Wernsdorfer,;1; Supramolecular spin valves., Nat. Mater. 10 (2011) 502-6.

[4] H. Heersche, Z. de Groot, J. Folk, H. van der Zant, C. Romeike, M. Wegewijs, L. Zobbi, D. Barreca, E. Tondello,;1; a. Cornia, Electron Transport through Single Mn12 Molecular Magnets, Phys. Rev. Lett. 96 (2006) 206801.

[5] M.N. Leuenberger, D. Loss,;1; Quantum computing in molecular magnets., Nature. 410 (2001) 789-93.

[6] A. Cornia, M. Mannini, P. Sainctavit, R. Sessoli,;1; Chemical strategies and characterization tools for the organization of single molecule magnets on surfaces, Chem. Soc. Rev. 40 (2011) 3076-91.

[7] A. Cornia, A. Costantino, L. Zobbi, A. Caneschi, D. Gatteschi, M. Mannini, R. Sessoli,;1; Preparation of Novel Materials Using SMMs, Single-Molecule Magnets Relat. Phenom. 122 (2006) 133-161.

[8] A.L. Barra, A. Caneschi, A. Cornia, F. Fabrizi de Biani, D. Gatteschi, C. Sangregorio, R. Sessoli, L. Sorace,; 1; Single-Molecule Magnet Behavior of a Tetranuclear Iron(III) Complex. The Origin of Slow Magnetic Relaxation in Iron(III) Clusters, J. Am. Chem. Soc. 121 (1999) 5302-5310.

[9] S. Accorsi, A. Barra, A. Caneschi, G. Chastanet, A. Cornia, A.C. Fabretti, D. Gatteschi, C. Mortalò, E. Olivieri, F. Parenti, P. Rosa, R. Sessoli, L. Sorace, W. Wernsdorfer, L. Zobbi,;1; Tuning anisotropy barriers in a family of tetrairon (III) single-molecule magnets with an $S=5$ ground state, J. Am. Chem. Soc. 128 (2006) 4742-4755.

[10] A.-L. Barra, F. Bianchi, A. Caneschi, A. Cornia, D. Gatteschi, L. Gorini, L. Gregoli, M. Maffini, F. Parenti, R. Sessoli, L. Sorace, A.M. Talarico,;1; New Single-Molecule Magnets by Site-Specific Substitution: Incorporation of "Alligator Clips" into Fe4 Complexes, Eur. J. Inorg. Chem. 2007 (2007) 4145-4152.

[11] M. Mannini, F. Pineider, P. Sainctavit, C. Danieli, E. Otero, C. Sciancalepore, A.M. Talarico, M.-A. Arrio, A. Cornia, D. Gatteschi, R. Sessoli,;1; Magnetic memory of a single-molecule quantum magnet wired to a gold surface., Nat. Mater. 8 (2009) 194-7.

[12] M. Mannini, F. Pineider, C. Danieli, F. Totti, L. Sorace, P. Sainctavit, M. Arrio, E. Otero, L. Joly, J.C. Cezar, a Cornia, R. Sessoli,;1; Quantum tunnelling of the magnetization in a monolayer of oriented single-molecule magnets., Nature. 468 (2010) 417-21.

[13] L. Malavolti, V. Lanzilotto, S. Ninova, L. Poggini, I. Cimatti, B. Cortigiani, L. Margheriti, D. Chiappe, E. Otero, P. Sainctavit, F. Totti, A. Cornia, M. Mannini, R. Sessoli,; ; Magnetic Bistability in a Submonolayer of Sublimated Fe 4 Single Molecule Magnets, Nano Lett. 15 (2015) 535-541.

[14] V. Lanzilotto, L. Malavolti, S. Ninova, I. Cimatti, L. Poggini, B. Cortigiani, M. Mannini, F. Totti, A. Cornia, R. Sessoli,;1; The Challenge of Thermal Deposition of Coordination Compounds: Insight into the Case of an Fe 4 Single Molecule Magnet, Chem. Mater. 28 (2016) 7693-7702.

[15] N. Ishikawa, M. Sugita, W. Wernsdorfer,;1; Quantum tunneling of magnetization in lanthanide single-molecule magnets: bis(phthalocyaninato)terbium and bis(phthalocyaninato)dysprosium anions., Angew. Chem. Int. Ed. Engl. 44 (2005) 2931-5.

[16] C. Wäckerlin, F. Donati, A. Singha, R. Baltic, S. Rusponi, K. Diller, F. Patthey, M. Pivetta, Y. Lan, S. Klyatskaya, M. Ruben, H. Brune, J. Dreiser,;1; Giant Hysteresis of Single-Molecule Magnets Adsorbed on a Nonmagnetic Insulator, Adv. Mater. 28 
(2016) 5195-5199.

[17] L. Malavolti, M. Mannini, P. Car, G. Campo, F. Pineider, R. Sessoli,;1; Erratic magnetic hysteresis of TbPc2 molecular nanomagnets, J. Mater. Chem. C. 1 (2013) 2935-2942.

[18] L. Margheriti, D. Chiappe, M. Mannini, P.-E. Car, P. Sainctavit, M.-A. Arrio, F.B. de Mongeot, J.C. Cezar, F.M. Piras, A. Magnani, E. Otero, A. Caneschi, R. Sessoli,;1; Xray detected magnetic hysteresis of thermally evaporated terbium double-decker oriented films., Adv. Mater. 22 (2010) 5488-93.

[19] F. Habib, M. Murugesu,;1; Lessons learned from dinuclear lanthanide nano-magnets, Chem. Soc. Rev. 42 (2013) 3278-3288.

[20] W.-H. Zhu, S. Li, C. Gao, X. Xiong, Y. Zhang, L. Liu, A.K. Powell, S. Gao,;1; Lanthanide dinuclear complexes constructed from mixed oxygen-donor ligands: the effect of substituent positions of the neutral ligand on the magnetic dynamics in Dy analogues, Dalt. Trans. 45 (2016) 4614-4621.

[21] W.-Y. Zhang, Y.-M. Tian, H.-F. Li, P. Chen, W.-B. Sun, Y.-Q. Zhang, P.-F. Yan,;1; A series of dinuclear Dy(iii) complexes bridged by 2-methyl-8-hydroxylquinoline: replacement on the periphery coordinated [small beta]-diketonate terminal leads to different single-molecule magnetic properties, Dalt. Trans. 45 (2016) 3863-3873.

[22] J. Zhang, H. Zhang, Y. Chen, X. Zhang, Y. Li, W. Liu, Y. Dong,;1; A series of dinuclear lanthanide complexes with slow magnetic relaxation for Dy2 and Ho2, Dalt. Trans. 45 (2016) 16463-16470.

[23] W. Yu, F. Schramm, E.M. Pineda, Y. Lan, O. Fuhr, J. Chen, H. Isshiki, W. Wernsdorfer, W. Wulfhekel, M. Ruben,;1; Single-molecule magnet behavior in 2,2'-bipyrimidinebridged dilanthanide complexes, Beilstein J. Nanotechnol. 7 (2016) 126-137.

[24] X. Yi, J. Shang, L. Pan, H. Tan, B. Chen, G. Liu, G. Huang, K. Bernot, O. Guillou, R.-W. Li,;1; Reversible Luminescence Modulation upon an Electric Field on a Full SolidState Device Based on Lanthanide Dimers, ACS Appl. Mater. Interfaces. 8 (2016) 15551-6.

[25] Y.-L. Wang, C.-B. Han, Y.-Q. Zhang, Q.-Y. Liu, C.-M. Liu, S.-G. Yin,;1; Fine-Tuning Ligand to Modulate the Magnetic Anisotropy in a Carboxylate-Bridged Dy2 SingleMolecule Magnet System, Inorg. Chem. 55 (2016) 5578-5584.

[26] W.-M. Wang, W.-Z. Qiao, H.-X. Zhang, S.-Y. Wang, Y.-Y. Nie, H.-M. Chen, Z. Liu, H.L. Gao, J.-Z. Cui, B. Zhao,;1; Structures and magnetic properties of several phenoxo-O bridged dinuclear lanthanide complexes: Dy derivatives displaying substituent dependent magnetic relaxation behavior, Dalt. Trans. 45 (2016) 8182-8191.

[27] W. Sun, B. Yan, L. Jia, B.-W. Wang, Q. Yang, X. Cheng, H. Li, P. Chen, Z. Wang, S. Gao,;1; Dinuclear Dysprosium SMMs Bridged by Neutral Bipyrimidine Ligand: Two Crystal Systems Depend on Different Lattice Solvents Lead to Distinct Slow Relaxation Behaviour, Dalt. Trans. 45 (2016) 8790-8794.

[28] I. Oyarzabal, B. Fernandez, J. Cepeda, S. Gomez-Ruiz, A.J. Calahorro, J.M. Seco, A. Rodriguez-Dieguez,; ; Slow relaxation of magnetization in 3D-MOFs based on dysprosium dinuclear entities bridged by dicarboxylic linkers, CrystEngComm. 18 (2016) 3055-3063.

[29] S. Benmansour, G. López-Martínez, J. Canet-Ferrer, C. Gómez-García;;1; A Family of Lanthanoid Dimers with Nitroanilato Bridges, Magnetochemistry. 2 (2016) 32.

[30] X. Yi, G. Calvez, C. Daiguebonne, O. Guillou, K. Bernot,;1; Rational Organization of Lanthanide-Based SMM Dimers into Three-Dimensional Networks, Inorg. Chem. 54 (2015) 5213-5219.

[31] W.-M. Wang, H.-X. Zhang, S.-Y. Wang, H.-Y. Shen, H.-L. Gao, J.-Z. Cui, B. Zhao,;1; Ligand Field Affected Single-Molecule Magnet Behavior of Lanthanide(III) Dinuclear Complexes with an 8-Hydroxyquinoline Schiff Base Derivative as Bridging Ligand, Inorg. Chem. 54 (2015) 10610-10622. 
[32] Y. Peng, V. Mereacre, A. Baniodeh, Y. Lan, M. Schlageter, G.E. Kostakis, A.K. Powell,;1; Effect of Ligand Field Tuning on the SMM Behavior for Three Related Alkoxide-Bridged Dysprosium Dimers, Inorg. Chem. 55 (2015) 68-74.

[33] S.-Y. Lin, J. Wu, C. Wang, L. Zhao, J. Tang,;1; Modulating Relaxation Dynamics of Dy2 Compounds through Carboxylate Coordination Modes, Eur. J. Inorg. Chem. (2015) 5488-5494.

[34] P. Comba, M. Großhauser, R. Klingeler, C. Koo, Y. Lan, D. Müller, J. Park, A. Powell, M.J. Riley, H. Wadepohl,;1; Magnetic Interactions in a Series of Homodinuclear Lanthanide Complexes, Inorg. Chem. 54 (2015) 11247-11258.

[35] K. Suzuki, R. Sato, N. Mizuno,;1; Reversible switching of single-molecule magnet behaviors by transformation of dinuclear dysprosium cores in polyoxometalates, Chem. Sci. 4 (2013) 596-600.

[36] M. Ren, S.-S. Bao, N. Hoshino, T. Akutagawa, B. Wang, Y.-C. Ding, S. Wei, L.-M. Zheng,;1; Solvent Responsive Magnetic Dynamics of a Dinuclear Dysprosium SingleMolecule Magnet, Chem. Eur. J. 19 (2013) 9619-9628.

[37] F. Habib, G. Brunet, V. Vieru, I. Korobkov, L.F. Chibotaru, M. Murugesu,;1; Significant Enhancement of Energy Barriers in Dinuclear Dysprosium Single-Molecule Magnets Through Electron-Withdrawing Effects, J. Am. Chem. Soc. 135 (2013) 13242-13245.

[38] F. Pointillart, Y. Le Gal, S. Golhen, O. Cador, L. Ouahab,; 1; Single-Molecule Magnet Behaviour in a Tetrathiafulvalene-Based Electroactive Antiferromagnetically Coupled Dinuclear Dysprosium(III) Complex, Chem. Eur. J. 17 (2011) 10397-10404.

[39] J. Long, F. Habib, P. Lin, I. Korobkov, G. Enright, L. Ungur, W. Wernsdorfer, L.F. Chibotaru, M. Murugesu,;1; Single-Molecule Magnet Behavior for an Antiferromagnetically Superexchange-Coupled Dinuclear Dysprosium ( III ) Complex, J. Am. Chem. Soc. (2011) 5319-5328.

[40] P.H. Lin, T.J. Burchell, R. Clerac, M. Murugesu,;1; Dinuclear Dysprosium(III) SingleMolecule Magnets with a Large Anisotropic Barrier, Angew. Chemie 47 (2008) 88488851.

[41] X. Yi, K. Bernot, O. Cador, J. Luzon, G. Calvez, C. Daiguebonne, O. Guillou,;1; Influence of ferromagnetic connection of Ising-type DyIII-based single ion magnets on their magnetic slow relaxation, Dalt. Trans. 42 (2013) 6728-6731.

[42] C.Y. Chow, H. Bolvin, V.E. Campbell, R. Guillot, J.W. Kampf, W. Wernsdorfer, F. Gendron, J. Autschbach, V.L. Pecoraro, T. Mallah,; 1; Assessing the exchange coupling in binuclear lanthanide(iii) complexes and the slow relaxation of the magnetization in the antiferromagnetically coupled Dy2 derivative, Chem. Sci. 6 (2015) 4148-4159.

[43] K. Zhang, D. Liu, V. Vieru, L. Hou, B. Cui, F.-S. Guo, L.F. Chibotaru, Y.-Y. Wang,;1; Transitions of two magnetic interaction states in dinuclear Dy(iii) complexes via subtle structural variations, Dalt. Trans. 46 (2017) 638-642.

[44] E. Moreno Pineda, N.F. Chilton, R. Marx, M. Dörfel, D.O. Sells, P. Neugebauer, S.-D. Jiang, D. Collison, J. van Slageren, E.J.L. McInnes, R.E.P. Winpenny,;1; Direct measurement of dysprosium(III)dysprosium(III) interactions in a single-molecule magnet, Nat Commun. 5 (2014).

[45] X. Yi, K. Bernot, F. Pointillart, G. Poneti, G. Calvez, C. Daiguebonne, O. Guillou, R. Sessoli,; 1; A luminescent and sublimable Dy(III)-based single-molecule magnet., Chem. Eur. J. 18 (2012) 11379-87.

[46] E. Kiefl, M. Mannini, K. Bernot, X. Yi, A. Amato, T. Leviant, A. Magnani, T. Leviant, T. Prokscha, A. Suter, R. Sessoli, Z. Salman,;1; Robust magnetic properties of a sublimable single molecule magnet, ACS Nano. 10 (2016) 5663-9.

[47] S.S. Nagarkar, B. Joarder, A.K. Chaudhari, S. Mukherjee, S.K. Ghosh,;1; Highly selective detection of nitro explosives by a luminescent metal-organic framework, Angew. Chemie - Int. Ed. 52 (2013) 2881-2885. 
[48] K.S. Asha, K. Bhattacharyya, S. Mandal,;1; Discriminative detection of nitro aromatic explosives by a luminescent metal-organic framework, J. Mater. Chem. C. 2 (2014) 10073-10081.

[49] S. Alvarez, P. Alemany, D. Casanova, J. Cirera, M. Llunell, D. Avnir,;1; Shape maps and polyhedral interconversion paths in transition metal chemistry, Coord. Chem. Rev. 249 (2005) 1693-1708.

[50] D. Casanova, J. Cirera, M. Llunell, P. Alemany, D. Avnir, S. Alvarez,;1; Minimal Distortion Pathways in Polyhedral Rearrangements, J. Am. Chem. Soc. 126 (2004) 1755-1763.

[51] D. Barreca, A. Gasparotto, A. Milanov, E. Tondello, A. Devi,;1; R. a. Fischer, Nanostructured Dy2O3 films: An XPS Investigation, Surf. Sci. Spectra. 14 (2007) 52.

[52] A.P. Milanov, R.W. Seidel, D. Barreca, A. Gasparotto, M. Winter, J. Feydt, S. Irsen, H.W. Becker, A. Devi,;1; Malonate complexes of dysprosium: synthesis, characterization and application for LI-MOCVD of dysprosium containing thin films., Dalton Trans. 40 (2011) 62-78.

[53] K. Roodenko, M. Gensch, J. Rappich, K. Hinrichs, N. Esser, R. Hunger,;1; Timeresolved synchrotron XPS monitoring of irradiation-induced nitrobenzene reduction for chemical lithography., J. Phys. Chem. B. 111 (2007) 7541-9.

[54] D. Popovici, G. Czeremuzkin, M. Meunier, E. Sacher,;1; Laser-induced metal-organic chemical vapor deposition (MOCVD) of $\mathrm{Cu}(\mathrm{hfac})$ (TMVS) on amorphous Teflon AF1600: an XPS study of the interface, Appl. Surf. Sci. 126 (1998) 198-204.

[55] S. Bag, K. Roy, C.S. Gopinath, C.R. Raj,;1; Facile Single-Step Synthesis of NitrogenDoped Reduced Graphene Oxide-Mn 3 O 4 Hybrid Functional Material for the Electrocatalytic Reduction of Oxygen, ACS Appl. Mater. Interfaces 6 (2014) 26922699.

[56] C. Gao, Q. Yang, B.-W. Wang, Z.-M. Wang, S. Gao,;1; Evaporable lanthanide single-ion magnet, CrystEngComm. 18 (2016) 4165-4171.

[57] A. Lunghi, F. Totti, R. Sessoli, S. Sanvito,;1; The role of anharmonic phonons in underbarrier spin relaxation of Single Molecule Magnet, Nat. Commun. (2017) $10.1038 /$ ncomms 14620.

[58] F. Habib, P. Lin, I. Korobkov, G. Enright, L. Ungur, W. Wernsdorfer, L.F. Chibotaru, M. Murugesu,;1; Single-Molecule Magnet Behavior for an Antiferromagnetically Superexchange-Coupled Dinuclear Dysprosium ( III ) Complex, (2011) 5319-5328.

[59] R.A. Layfield, J.J.W. McDouall, S.A. Sulway, F. Tuna, D. Collison, R.E.P. Winpenny,;1; Influence of the N-Bridging Ligand on Magnetic Relaxation in an Organometallic Dysprosium Single-Molecule Magnet, Chem. A Eur. J. 16 (2010) 4442-4446.

[60] K. Bernot, L. Bogani, A. Caneschi, D. Gatteschi, R. Sessoli,;1; A Family of Rare-EarthBased Single Chain Magnets:Playing with Anisotropy, J. Am. Chem. Soc. 128 (2006) 7947-7956.

[61] D.A. Shirley,;1; High-Resolution X-Ray Photoemission Spectrum of the Valence Bands of Gold, Phys. Rev. B. 5 (1972) 4709-4714.

[62] F. Aquilante, L. De Vico, N. Ferré, G. Ghigo, P.-Å Malmqvist, P. Neogràdy, T.B. Pedersen, M. Pitonàk, M. Reiher, B.O. Roos, L. Serrano-Andrés, M. Urban, V. Veryazov, R. Lindh,;1; MOLCAS 7: The Next Generation, J. Comput. Chem. 31 (2010).

[63] B.O. Roos, P.R. Taylor, P.E.M. Sigebahn,;1; A complete active space SCF method (CASSCF) using a density matrix formulated super-CI approach, Chem. Phys. 48 (1980) 157-173.

[64] P.Å. Malmqvist, B.O. Roos, B. Schimmelpfennig,;1; The restricted active space (RAS) state interaction approach with spin-orbit coupling, Chem Phys. Lett. 357 (2002) 230240. 
[65] P.-Å. Malmqvist, B.O. Roos,; 1; The CASSCF state interaction method, Chem. Phys. Lett. 155 (1989) 189-194.

[66] L.F. Chibotaru, L. Ungur,;1; Ab initio calculation of anisotropic magnetic properties of complexes. I. Unique definition of pseudospin Hamiltonians and their derivation, J. Chem. Phys. 137 (2012) 64112.

[67] L.F. Chibotaru, L. Ungur, A. Soncini,;1; The Origin of Nonmagnetic Kramers Doublets in the Ground State of Dysprosium Triangles: Evidence for a Toroidal Magnetic Moment, Angew. Chemie 47 (2008) 4126-4129.

[68] F. Aquilante, P.-Å. Malmqvist, T.B. Pedersen, A. Ghosh, B.O. Roos,;1; Cholesky Decomposition-Based Multiconfiguration Second-Order Perturbation Theory (CD-

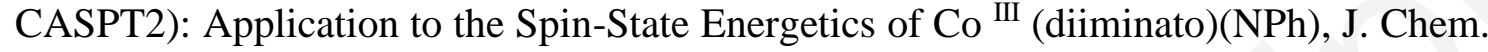
Theory Comput. 4 (2008) 694-702.

[69] Björn O. Roos, Per-Åke Malmqvist, A. Valera Veryazov, P.-O. Widmark,;1; Main Group Atoms and Dimers Studied with a New Relativistic ANO Basis Set, J. Phys. Chem. A. 108 (2004) 2851-2858.

[70] B.O. Roos, R. Lindh, P.-Å. Malmqvist, V. Veryazov, P.-O. Widmark, A.C. Borin,;1; New Relativistic Atomic Natural Orbital Basis Sets for Lanthanide Atoms with Applications to the Ce Diatom and $\mathrm{LuF}_{3}$, J. Phys. Chem. A. 112 (2008) 11431-11435.

[71] Björn O. Roos, Roland Lindh, Per-Åke Malmqvist, A. Valera Veryazov, P.-O. Widmark,;1; New Relativistic ANO Basis Sets for Transition Metal Atoms, J. Phys. Chem. A. 109 (2005) 6575-6579. 


\section{Captions}

Figure $1 \mathrm{a})$ Representation of the $\left[\mathrm{Dy}(\mathrm{hfac})_{3}\left(\mathrm{PyNO}-\mathrm{NO}_{2}\right)\right]_{2}$ molecule (hydrogen atoms are omitted for clarity) b) Coordination environment of the Dy ${ }^{\mathrm{III}}$ ion with calculated easy magnetic axis as orange arrows.

Figure 2 ToF-SIMS spectrum of the film (in red) and the bulk reference (in blue). In the bottom part there are two zoomed regions.

Figure 3 XPS region of Dy $4 d$ and O $1 s$ for DyPyNO-NO $\mathrm{N}_{2}$ film and bulk.

Figure 4 Frequency dependence of the in-phase $\left(\chi_{\mathrm{M}}\right.$ ', top) and out-of phase $\left(\chi_{\mathrm{M}}\right.$ ', , bottom) component of the magnetization of $\left[\mathrm{Dy}(\mathrm{hfac})_{3}\left(\mathrm{PyNO}-\mathrm{NO}_{2}\right)\right]_{2}$ as bulk (left) and as film (right) measured in zero static magnetic field. Color mapping from 1.8 (blue) to $20 \mathrm{~K}$ (red).

Figure 5 (Left) Arrhenius plot of DyPyNO-NO 2 as bulk (black squares) and film (red squares) and comparison with DyPyNO as bulk (triangles). The data of DyPyNO have been already reported in [46], but here the data are fitted using equation 1. (Right) Hysteresis loops recorded at $0.5 \mathrm{~K}$ for DyPyNO-NO 2 as bulk (black) and as film (red). 


\section{Tables}

Table 1. Semi-quantitative analysis of DyPyNO-NO 2 as film and bulk.

\begin{tabular}{|r|c|c|c|c|c|c|}
\hline & $\boldsymbol{F}$ 1s & Dy 4d & $\boldsymbol{C} 1 s$ & O 1s & N 1s & F1s/N1s \\
\hline theoretical & $36.0 \%$ & $2.0 \%$ & $40.0 \%$ & $18.0 \%$ & $4.0 \%$ & 9 \\
\hline evaporated & $35.7 \%$ & $2.8 \%$ & $46.3 \%$ & $15.2 \%$ & $3.7 \%$ & 9.6 \\
\hline
\end{tabular}


Table 2. Main dynamical parameters extracted for DyPyNO-NO $\mathrm{N}_{2}$ as bulk and film. Comparison with DyPyNO as bulk is provided [45].

\begin{tabular}{|c|c|c|c|}
\hline & $\begin{array}{c}\text { DyPyNO } \\
\text { bulk }\end{array}$ & $\begin{array}{c}\text { DyPyNO- } \\
\text { NO2 bulk }\end{array}$ & $\begin{array}{c}\text { DyPyNO- } \\
\text { NO }_{2} \text { film }\end{array}$ \\
\hline $\begin{array}{c}\text { Energy barrier } \\
\Delta\end{array}$ & $166 \mathrm{~K}$ & $204 \mathrm{~K}$ & - \\
\hline $\begin{array}{c}\text { Characteristic relaxation time } \\
\tau_{0}\end{array}$ & $6.6410^{-11}$ & $3.110^{-10} \mathrm{~s}$ & - \\
\hline $\begin{array}{c}\text { Relaxation time at 1.8K } \\
\tau_{1.8 \mathrm{~K}}\end{array}$ & $0.42 \mathrm{~s}$ & $2.1 \mathrm{~s}$ & - \\
\hline $\begin{array}{c}\text { Distribution of } \tau \\
\alpha(\text { max-min) }\end{array}$ & $0.05-0.007$ & $0.42-0.07$ & $0.26-0.03$ \\
\hline $\begin{array}{c}\text { Non-relaxing fraction at lowest T } \\
\mathrm{X}_{\mathrm{S}} / \mathrm{X}_{\mathrm{T}}\end{array}$ & $8.8 \%$ & $3.7 \%$ & $5.1 \%$ \\
\hline
\end{tabular}



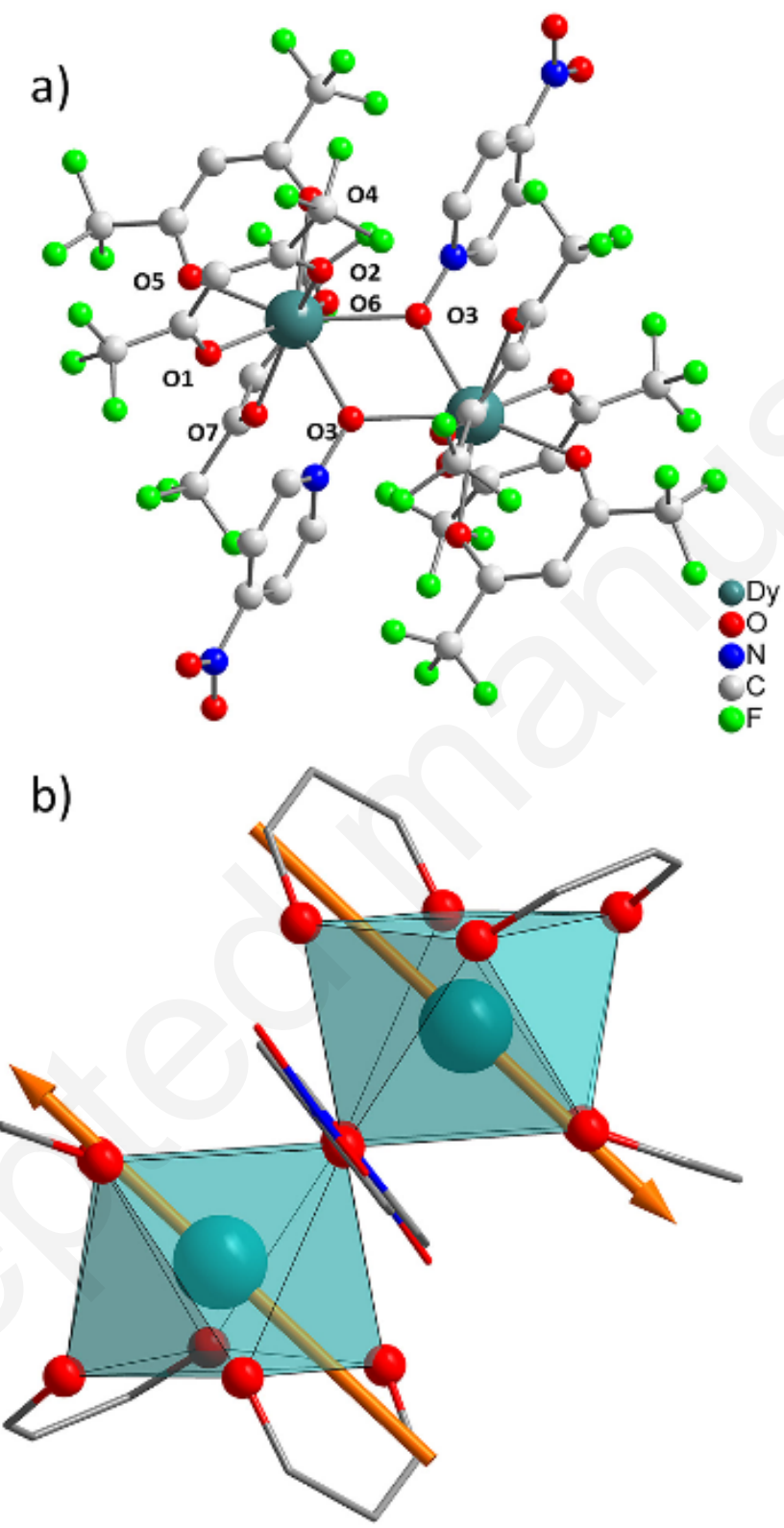

Fig. 1. a) Representation of the $\left[\mathrm{Dy}(\mathrm{hfac})_{3}\left(\mathrm{PyNO}-\mathrm{NO}_{2}\right)\right]_{2}$ molecule (hydrogen atoms are omitted for clarity) b) Coordination environment of the Dy"ll ion with calculated easy magnetic axis as orange arrows. (For interpretation of the references to colour in this figure legend, the reader is referred to the web version of this article,) 

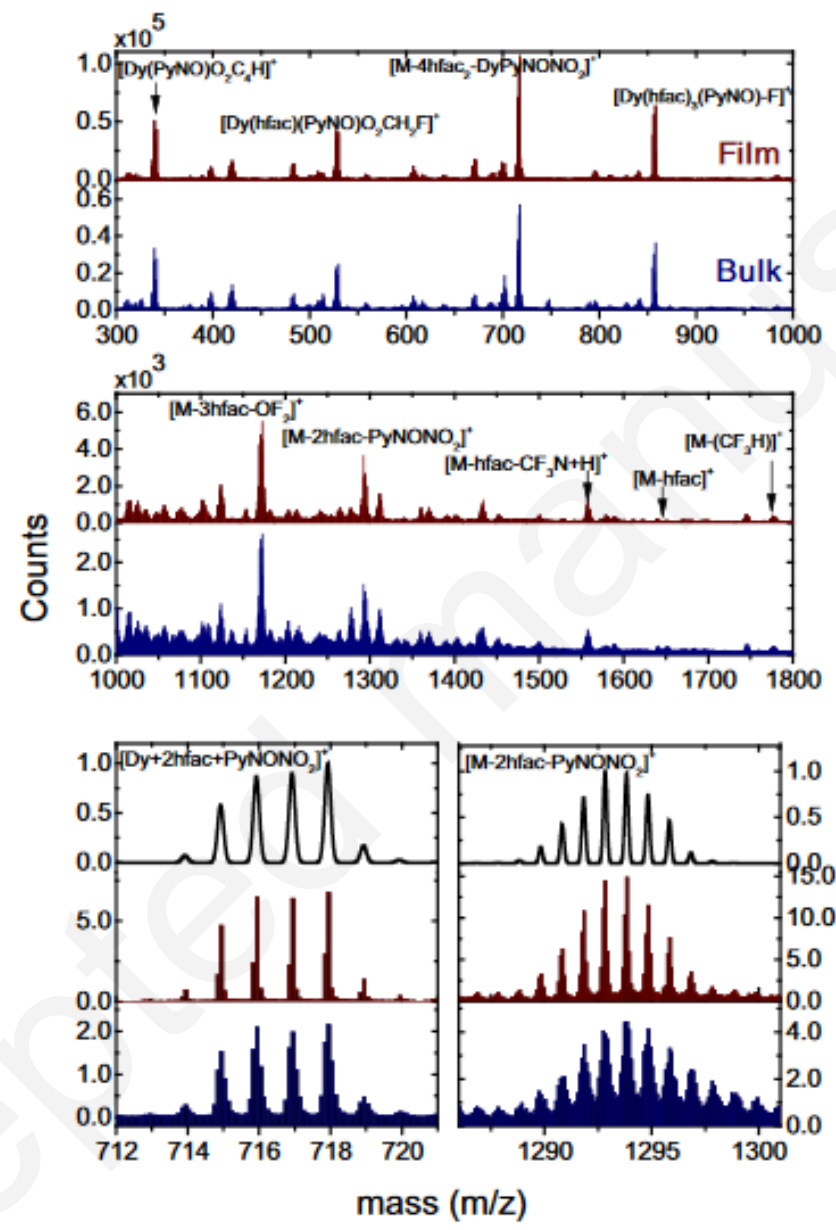

Fig. 2. ToF-SIMS spectrum of the film (in red) and the bulk reference (in blue). In the bottom part there are two zoomed regions where, from top to bottom, there are: theoretical, film and bulk pattern. (For interpretation of the references to colour in this figure legend, the reader is referred to the web version of this article.) 

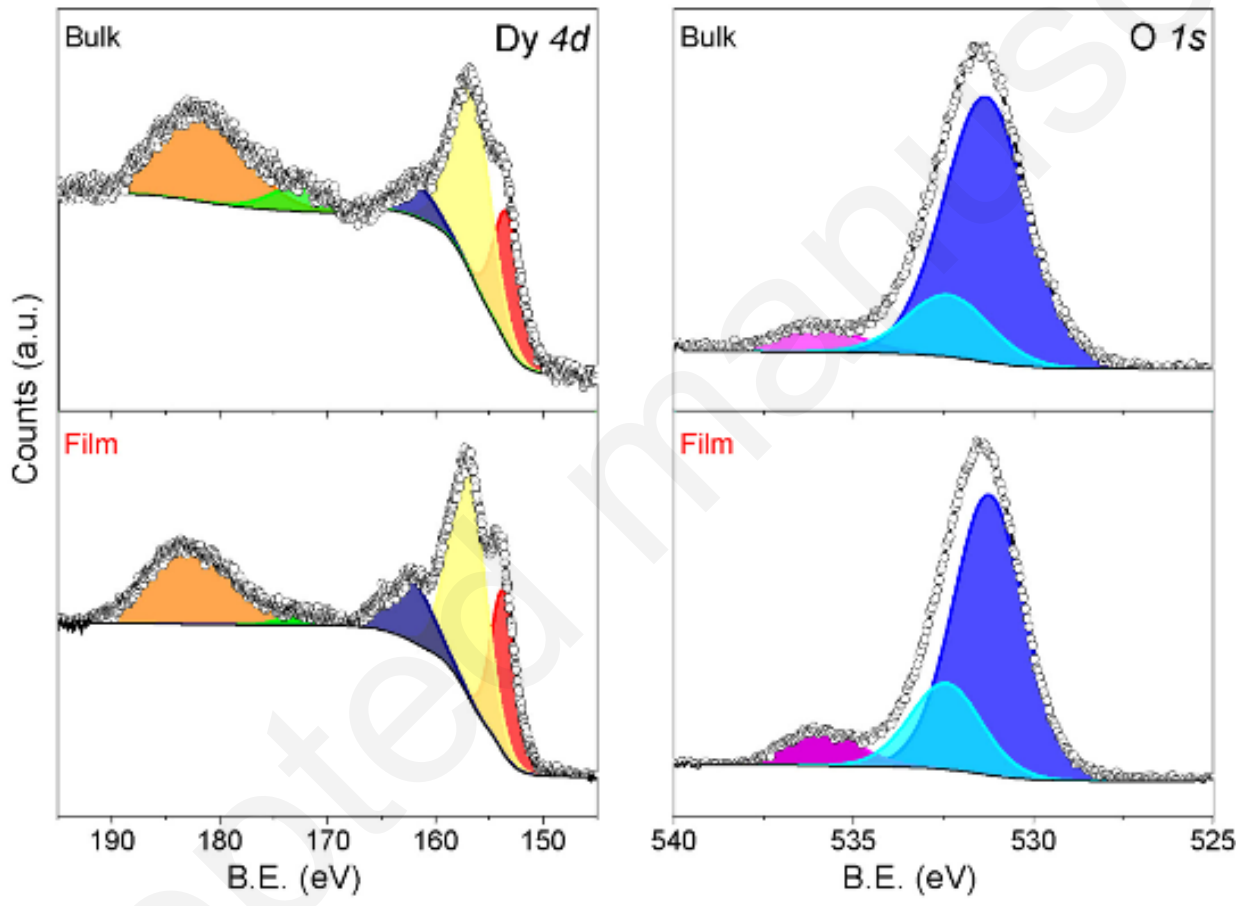

Fig. 3. XPS region of Dy $4 d$ and 0 1s for DyPyNO-NO ${ }_{2}$ film and bulk. 


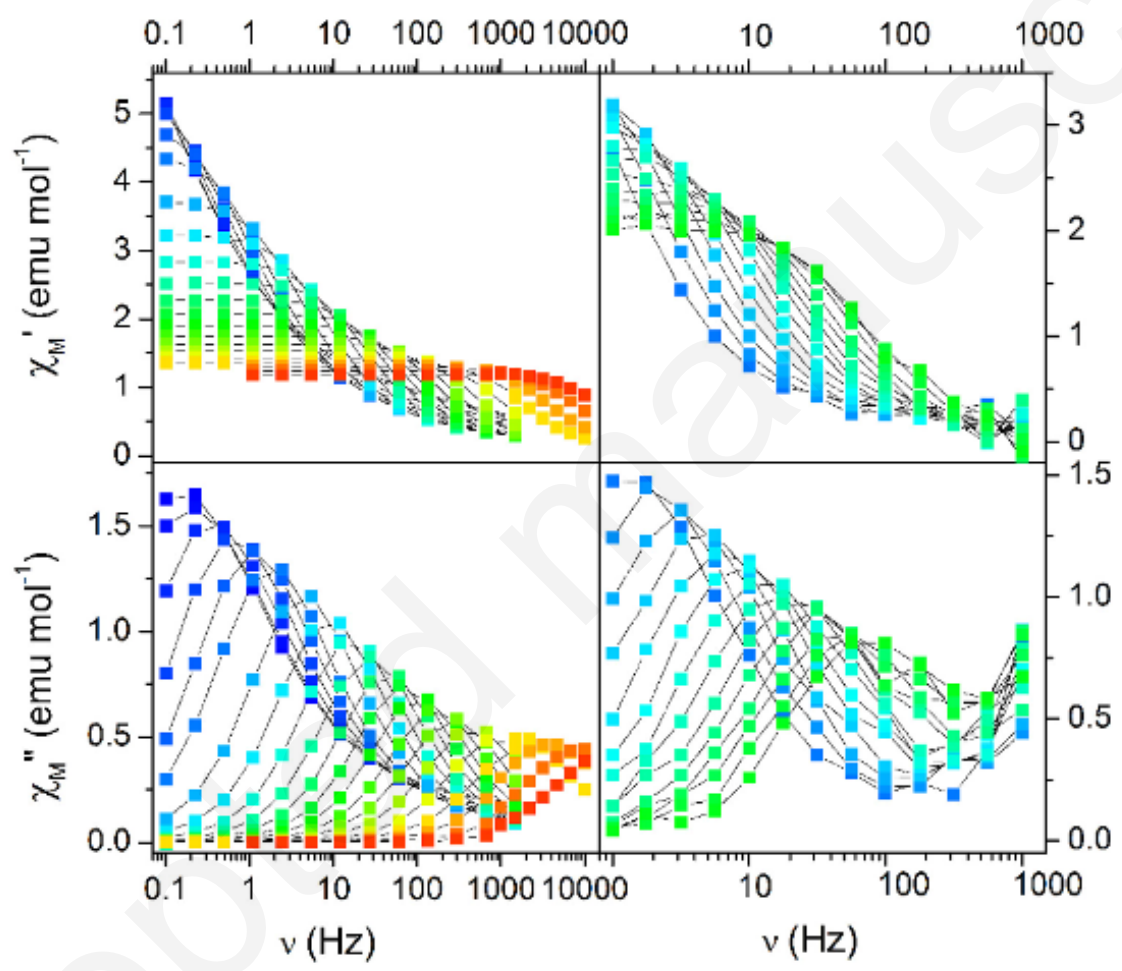

Fig. 4. Frequency dependence of the in-phase ( $\chi_{\mathrm{M}^{\prime}}$, top) and out-of phase ( $\chi_{\mathrm{M}^{\prime \prime}}$, bottom) component of the magnetization of $\left[\mathrm{DDy}\left(\mathrm{hfac}_{3}\right)_{3}\left(\mathrm{PyNO}_{\mathrm{N}} \mathrm{NO}_{2}\right)_{2}\right.$ as bulk (left) and as film (right) measured in zero static magnetic field, Color mapping from 1.8 (blue) to $20 \mathrm{~K}$ (red). (For interpretation of the references to colour in this figure legend, the reader is referred to the web version of this article,) 

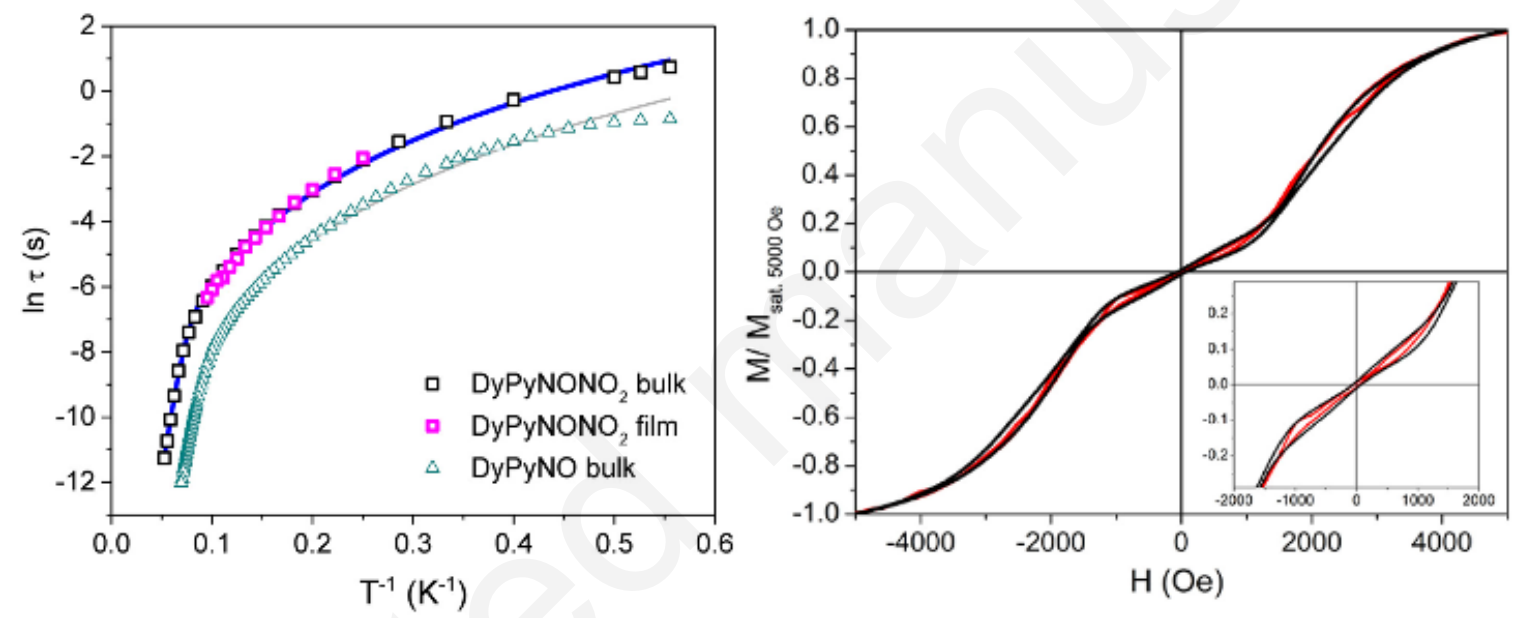

Fig. 5. (Left) Arrhenius plot of DyPyNO-NO 2 as bulk (black squares) and film (red squares) and comparison with DyPyNO as bulk (triangles). The data of DyPyNO have been already reported in [46], but here the data are fitted using equation 1. (Right) Hysteresis loops recorded at $0.5 \mathrm{~K}$ for DyPyNO-NO 2 as bulk (black) and as film (red). (For interpretation of the references to colour in this figure legend, the reader is referred to the web version of this article.)

Tables 